\title{
Asynchronous Learning Model in an ODL
}

\author{
Mirisoa Rakotomalala, \\ Phd School \\ Sciences and Technical Engineering and Innovation, \\ University of Antananarivo, \\ Teacher and Researcher at Higher Institute of Technology of Antananarivo \\ Antananarivo, Madagascar
}

Toky Basilide Ravaliminoarimalalason, Phd School

Sciences and Technical Engineering and Innovation, University of Antananarivo, Antananarivo, Madagascar

\begin{abstract}
The analysis of the traces of digital activity and the content analysis of a discussion forum on an Open and Distance Learning (ODL) platform form a database to be processed on $R$, in order to release an asynchronous learning model, according to the approach by Linear Structural Relation (LISREL) of Structural Equation Modeling (SEM).
\end{abstract}

Keywords - Model, Asynchronous learning, involvement, collaboration, educational outcome, $\mathrm{ODL}$

\section{INTRODUCTION}

The appropriation of methods and techniques of distance learning is not obvious to students. Also, most tutors do not help learners solve technical problems [1]. To fill all these gaps, a "Student Guide for Online Learning" (SGOL) entry module was designed and subsequently introduced in three open and distance learning courses. It aims to support learners in taking charge of the platform and provides the tools, advice and methods necessary to succeed in open and distance learning.

The idea of exploiting this instrument mainly has been advanced. Reinforcement of learning in ODL devices was envisaged, through modeling of learning engineering. It was within this framework that research was conducted and was based on the analysis of ODL. A study that coming from cognitive science, in the field of engineering science.

Modeling focuses on learners' knowledge management and data analysis on the platform. In other words, how to establish a model of Structural Equation Modeling (SEM), which can apply to any kind of open and distance learning, according to the analysis of traces of learning activities on a platform? The problem was about the distance learning system. The aim was to study the behavior of the learners in front of the discussion forum and to know if in an online teaching, the engagement in an interaction between students can be valued. Which model of asynchronous learning could be a tool for improving teaching effectiveness?

The aim of the study was to present an online learning model. To achieve this goal, firstly, the trace of asynchronous activities was analyzed, then a structure model based on SEM was developed.

\section{Falimanana Randimbindrainibe,} Phd School

Sciences and Technical Engineering and Innovation, University of Antananarivo, Antananarivo, Madagascar

\section{MATERIALS}

Data collection was conducted in 2016, 2017 and 2018. Three L3 ODLs of ISTs (IST: High Institute of Technology, in Madagascar) were used as research ground: Automatic System Engineering (ASE), Transit and International Trade (TIT) and Logistic Operations and Transportation (LOT). The distance learning initiation module called SGOL or "Student's Guide to Online Learning" was put into play. It contains four forums for discussion. A digital activity trace analysis grid was used with six promotions, 109 new learners, 12393 past events and 1072 messages to analyze.

\section{METHODOLOGIES}

A motivated learner communicates with his entourage in a training device, shares his knowledge via the platform, develops his know-how and his knowledge, and collaborates with the members of his group for a requested work. The evaluation of these three measurement variables in the learning of the initiation module made it possible to measure the latent variable "involvement" of the learner. Similarly, forum consultation, discussion consultation, learner participation by sending and updating messages, were all listed to be able to measure the learner's attitude when learning from a distance. Thus, the two models validated in [2] were used for all applications in the rest of the study, in order to leave the structure model of the research. Is there a causal relationship between the learner's involvement and his attitude in the discussion forum? Does involvement enable the development of learners' knowledge? Does the learners' attitude in the forum have a positive impact on their learning outcome? These are the different research questions that will be answered in this article.

\section{RESULTS}

The overall result of the research primarily covered the innovative strategy for distance learning. The expected result was the provision of an asynchronous learning model in ODL. This model can be adapted to the Malagasy context.

\section{A. Asynchronous learning model}

The structure model made it possible to examine the link between the different latent variables. The structural equation method represents a multivariate technique that combines measurement models and structural models while simultaneously examining a series of linear relationships 
between observed variables and latent variables on the one hand, and between sets of latent variables on the other hand [3].

\section{1) Model identification}

The data obtained from the analysis of digital traces of the activities and the content analysis of all existing forums were the basis of treatment on $\mathrm{R}$. The two latent variables $\mathrm{A}$ and $\mathrm{E}$ were determined from these analyzes according to the two previously validated measurement models [2]. The article presents the determination of the third latent variable $\mathrm{C}$, which has a direct relationship with the educational outcome of the training. Six cases are likely to happen for the model structure equation. The figure below shows the identified model:



Fig. 1. Identified structure model

\section{2) Structured model with estimated parameters}

The structure model below was obtained at the outcome of the processing of the first proposal. It was noticed that the model converges after 71 iterations.



Fig. 2. Structure model of the research

According to Fig. 2, the learner's involvement has a direct impact on his attitude in the discussion forum.

\section{B. Estimation of the result from the latent variable $C$}

Three latent variables were considered in this structure model: A for Attitude, $\mathrm{E}$ for Involvement and $\mathrm{C}$ for the Cognition.

The latent variable $\mathrm{C}$ has a relationship with the educational outcome of the learning. Let "Rm" be the result from the research model, and "Rr" the educational outcome of the learning. The result was 1 when the learner was admitted and was 0 when the learner failed (not admitted).



Fig. 3. Three latent variables of the research

This set of data was exported to Excel to perform a spreadsheet analysis.

\section{The threshold value from the probability distribution of $C$ and the actual result}

A threshold value $C_{\text {th }}$ of the latent variable $C$ was set to decide whether a learner was admitted or not. Depending on this threshold, the following table shows a comparison of the actual results with those of the model. It will be noted by TRUE if the real result of the learner is identical to the result predicted by the model (whether admitted or not), and by FALSE otherwise.

\begin{tabular}{|l|r|r|r|r|r|r|r|}
\hline Threshold of C & -0.9 & -1.0 & -1.1 & -1.2 & -1.3 & -1.4 & -1.5 \\
\hline TRUE & 72 & 72 & 73 & 73 & 73 & 71 & 71 \\
\hline FALSE & 24 & 24 & 23 & 23 & 23 & 25 & 25 \\
\hline $\begin{array}{l}\text { Number of } \\
\text { admitted learners } \\
\text { according to the } \\
\text { model }\end{array}$ & 42 & 42 & 43 & 45 & 45 & 47 & 49 \\
\hline $\begin{array}{l}\text { Number of } \\
\text { actually admitted } \\
\text { learners }\end{array}$ & 46 & 46 & 46 & 46 & 46 & 46 & 46 \\
\hline
\end{tabular}

Fig. 4. Threshold of C

According to the Table in Figure 4. a maximum of likelihood can be deduced between the results of the model and the actual results for a threshold value ranging from $C_{\text {th }}=-1.1$ to -1.3 . The exact value of the threshold to be adopted can be determined from the distribution of the values of these two types of results in the following paragraph.

In the cases where $C_{\text {th }}=-1.2$ or $C_{\text {th }}=-1.3$, a similarity regarding the number of learners admitted was also observed.

D. The pedagogical result in relation to Cognition according to the model

By taking $\mathrm{C}_{\text {th }}=-1.3$, the graph in the Figure below represents the decisions on the learners' result as a function of the "value of the latent variable C". 




Fig. 5. Processing of the Threshold on Excel

It was found, according to the graph on Fig. 5., that starting from the value " $\mathrm{C}_{\mathrm{th}}$ " threshold of the cognition, the model gave the result 1 , in other words, starting from the threshold value of the cognition, the learner has passed the training.

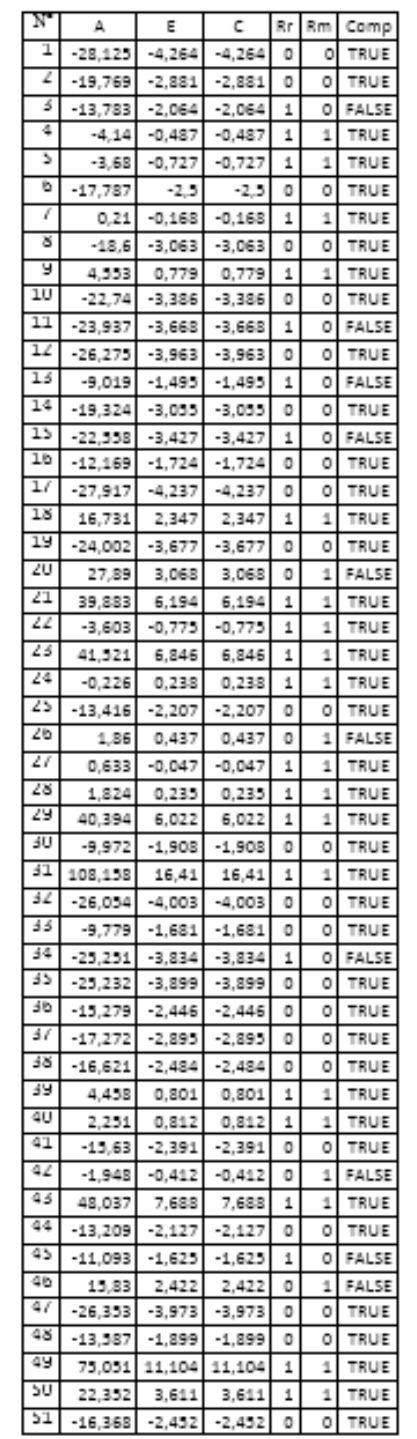

Fig. 6. Data processing on Excel



the rasult of the wodel of the molel dos not coincide with the rosult of the model
With R, it is also possible to determine this threshold. According to Fig. 7. below, using locator () R-function, $\mathrm{C}_{\text {th }}$ was -1.338 .

\section{QQ-plot C and Result}



Fig. 7. Distribution of the educational result

This last value was used in the following analysis.

\section{E. Results forecast for the current academic year}

Open and distance learning ASE is recruiting its second class in the 2017/2018 academic year. Fifteen new learners followed the tutorial of the SGOL introductory module at the beginning of the training. After the digital trace analysis of activities on SGOL, 2708 events were passed. The content analysis of 260 messages on forums made it possible to measure the latent variable $\mathrm{E}$, whereas the processing carried out from these events made it possible to measure A.

\begin{tabular}{|c|r|r|r|r|r|r|}
\hline Learner & \multicolumn{1}{|c|}{ COLLAB } & \multicolumn{1}{c|}{ COMM } & \multicolumn{1}{c|}{ MOTIV } & \multicolumn{1}{l}{ Consu_F } & Consu_D & Envoi_M \\
\hline$[1]$ & 11 & 4 & 1 & 44 & 90 & 42 \\
\hline$[2]$ & 11 & 3 & 1 & 48 & 48 & 36 \\
\hline$[3]$ & 10 & 4 & 2 & 37 & 85 & 41 \\
\hline$[4]$ & 11 & 3 & 2 & 62 & 89 & 43 \\
\hline$[5]$ & 20 & 6 & 1 & 123 & 125 & 72 \\
\hline$[6]$ & 5 & 3 & 1 & 21 & 71 & 29 \\
\hline$[7]$ & 13 & 6 & 5 & 66 & 152 & 60 \\
\hline$[8]$ & 5 & 4 & 1 & 12 & 27 & 20 \\
\hline$[9]$ & 10 & 8 & 1 & 71 & 114 & 53 \\
\hline$[10]$ & 13 & 5 & 3 & 88 & 129 & 56 \\
\hline$[11]$ & 10 & 4 & 2 & 31 & 71 & 38 \\
\hline$[12]$ & 16 & 3 & 1 & 53 & 129 & 60 \\
\hline$[13]$ & 2 & 1 & 1 & 10 & 26 & 9 \\
\hline$[14]$ & 14 & 4 & 1 & 19 & 65 & 39 \\
\hline$[15]$ & 21 & 6 & 1 & 39 & 101 & 64 \\
\hline
\end{tabular}

Legend:



Fig. 8. Data after trace and content analysis

As a result of the application of the research model, the result 10 admitted among the 15 new learners of the second class of ASE 2018 was obtained. 




Fig. 9. Result forecast for ASE 2018

\section{F. General prediction}

Data with values varying from 0 to 20 for each variable COLLAB, COMM, MOTIV, Consu_F, Consu_D, Envoi_M was created.

\begin{tabular}{|c|c|c|c|c|c|c|c|c|c|c|}
\hline & COLLAB & comn & MOTIV & Consu_F & \begin{tabular}{|l} 
Consu_d \\
\end{tabular} & Envoi_M & A & E & c & $\mathrm{R}$ \\
\hline 2607 & 0 & 20 & 0 & 20 & 5 & 10 & $-13,06$ & $-1,74$ & $-1,74$ & 0 \\
\hline 2608 & 0 & 20 & 0 & 20 & 5 & 15 & \begin{tabular}{|l|l|}
5 & $-10,87$ \\
\end{tabular} & $-1,46$ & $-1,46$ & 0 \\
\hline 2609 & 0 & 20 & 0 & 20 & 5 & 20 & \begin{tabular}{|l|l|} 
& $-8,69$ \\
\end{tabular} & $-1,19$ & $-1,19$ & 1 \\
\hline 2610 & 0 & 20 & 0 & 20 & 10 & 0 & $-16,66$ & $-2,19$ & $-2,19$ & 0 \\
\hline 2611 & 0 & 20 & 0 & 20 & 10 & 5 & \begin{tabular}{|l|l}
5 & $-14,47$ \\
\end{tabular} & $-1,92$ & $-1,92$ & 0 \\
\hline 2612 & 0 & 20 & 0 & 20 & 10 & 10 & $-12,29$ & $-1,64$ & $-1,64$ & 0 \\
\hline 2613 & 0 & 20 &  & 20 & 10 & 15 & $5-10,11$ & $-1,37$ & $-1,37$ & 0 \\
\hline 2614 & 0 & 20 & 0 & 20 & 10 & 20 & \begin{tabular}{|l|l|} 
& $-7,92$
\end{tabular} & $-1,09$ & $-1,09$ & 1 \\
\hline 2615 & 0 & 20 & 0 & 20 & 15 & 0 & $\mid-15,89$ & $-2,10$ & $-2,10$ & 0 \\
\hline 2616 & 0 & 20 & 0 & 20 & 15 & 5 & \begin{tabular}{|l|l|}
$5-13,71$ \\
\end{tabular} & $-1,82$ & $-1,82$ & 0 \\
\hline 2617 & 0 & 20 & 0 & 20 & 15 & 10 & $-11,52$ & $-1,55$ & $-1,55$ & 0 \\
\hline 2618 & 0 & 20 & 0 & 20 & 15 & 15 & \begin{tabular}{|l|l}
55 & $-9,34$ \\
\end{tabular} & $-1,27$ & $-1,27$ & 1 \\
\hline 2619 & 0 & 20 & 0 & 20 & 15 & 20 & $-7,15$ & $-0,99$ & $-0,99$ & 1 \\
\hline 2620 & 0 & 20 & 0 & 20 & 20 & 0 & $-15,12$ & $-2,00$ & $-2,00$ & 0 \\
\hline 2621 & 0 & 20 & 0 & 20 & 20 & 5 & $5 \mid-12,94$ & $-1,72$ & $-1,72$ & 0 \\
\hline 2622 & 0 & 20 & 0 & 20 & 20 & 10 & $-10,75$ & $-1,45$ & $-1,45$ & 0 \\
\hline 2623 & 0 & 20 & 0 & 20 & 20 & 15 & \begin{tabular}{|l|l|} 
& $-8,57$
\end{tabular} & $-1,17$ & $-1,17 \mid$ & 1 \\
\hline 2624 & 0 & 20 & 0 & 20 & 20 & 20 & $-6,39$ & $-0,90$ & $-0,90$ & 1 \\
\hline 2625 & 0 & 20 & 5 & 0 & 0 & 0 & $-18,97$ & $-2,15$ & $-2,15$ & 0 \\
\hline 2626 & 0 & 20 & 5 & 0 & 0 & 5 & \begin{tabular}{|l|l|}
5 & $-16,79$ \\
\end{tabular} & $-1,87$ & $-1,87$ & 0 \\
\hline 2627 & 0 & 20 & 5 & 0 & 0 & 10 & $-14,60$ & $-1,60$ & $-1,60$ & 0 \\
\hline 2628 & 0 & 20 & 5 & 0 & 0 & 15 & $5 \mid-12,42$ & $-1,32$ & $-1,32$ & 1 \\
\hline
\end{tabular}

Fig. 10. Extracts of data generated with the estimated values of variables $\mathrm{A}$, E, C and R

The results are summarized in the graphs in the following figure.



A result 1 indicates an admitted learner, while 0 indicates as always, a non-admitted learner.

In Fig. 11., the red marker on the ordinate 0 and abscissa 5 indicates that learners having brought COLLAB $=5$ failed. Above, the red marker on the ordinate 1 indicates that other learners having brought the same value of COLLAB are admitted, but obviously with other values of the other variables. The proportion between admitted and failed learners is: $91 \%$ admitted - 9\% failed.

From Fig. 12., it is noted that the proportions of admitted learners increase according to the values of the variables studied (example in Figure 5.19).

\section{Result as function of COMM}



Fig. 12. Increasing rate of admission depending on the variable

It can be deduced that the more learners bring more collaboration, the more they can be admitted. A motivated learner collaborates with his peers and always communicates with them during his learning. He always reads news, participates in ongoing discussions and creates much needed debates. The dynamism of the learner in collaboration and communication, the maintenance of motivation and the active participation in a discussion forum has a positive impact on his cognition and brings him a good pedagogical result.

For the observed variables generating the latent variable $\mathrm{A}$ (Consu_F, Consud_D, Envoi_M), it was noted that the rates of admitted learners do not vary much, as shown in Fig. 13.

Fig. 11. Result as function of each variable 


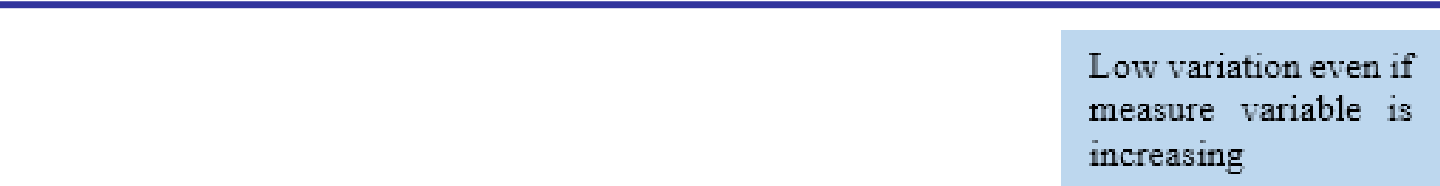

Result as function of . Consu_F

Fig. 13. Rate of admission with latent variable $\mathrm{A}$

It was deduced that the three measurement variables of the latent variable $\mathrm{A}$ do not have a direct impact on the latent variable $\mathrm{C}$, as well as on the pedagogical result of the learner. In other words, the student's behavior in front of the discussion forum does not have a direct influence on his / her acquisition of knowledge.

Participation in the ongoing discussion and any consultation of forums on the platform is not enough when learning in an

\section{Result as function of COLLAB}



ODL. It is necessary to react, and to always contribute to the collaboration in all the group activities of the training. It is also necessary to talk to the manager or teammates about the difficulty if there is one, so that they can help solve it and take the necessary action to keep perseverance motivated.

An interesting result can also be deduced from Fig. 11. It is highlighted in the Fig. 14. below.

\section{Result as function of MOTIV}

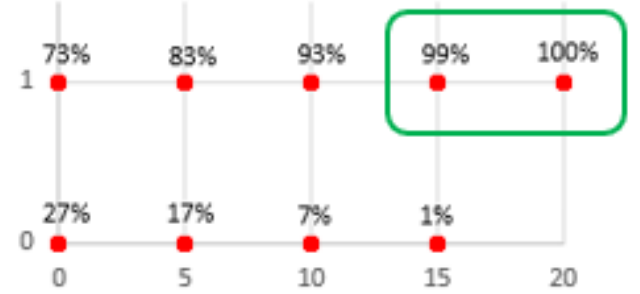

Fig. 14. Collaboration and motivation of learner

From a certain value of collaboration provided by a learner, that learner can always be admitted whatever the values of the other variables of measurement ( 0 failure). Collaboration is therefore a strong indicator for the latent variable $\mathrm{E}$ and has a significant impact on $\mathrm{C}$ and the educational outcome. In other words, collaboration favors a socio-constructivist vision of learning as part of the construction of knowledge [4], [5].

Afterwards, the motivation of a learner can also be mentioned. It creates a climate conducive for learning. Motivation is part of the social skills needed in e-learning. "The idea that we can build ourselves and rebuild ourselves, as we can partly build and rebuild the rest of society, permanently" [6]. A motivated learner communicates with his entourage in a training device, shares his knowledge via the platform, develops his know-how and his knowledge, and collaborates among the members of his group for the requested work.

The involvement of a learner in a group could support his asynchronous interaction and motivation in training.

It can be said that the involvement of the student must be serious to be successful in an ODL. The student should be active in collaborative work, interact with the peers, and he or she should be motivated by training and all learning activities.

\section{DISCUSSIONS}

Tutoring, if there is one, should then favor the collaboration of the learners to have a good result. According to Dix et al. [7], collaborative work is developed in pairs, and it would be better to present students with an organized forum than to suggest ways for them to organize it themselves.

\section{A. Remote collaboration in a structured forum}

In the context of collaborative remote discussion, learners use the forum tool to come up with a common solution [8] [9]; and they must argue to better understand their peers [10].

While the scenario has an important role to play in stimulating interaction between learners [11], it is also important to adapt the tools to the context of learning. The result of the research has approved the importance of this structuring, and the impact of collaborative work on the success of active learners.

Learners in distance education have brought nuances to collaborative working arrangements. Bruno De Lièvre and his colleague [12] have highlighted the fact that learners value and consider collaborative work to be beneficial. This nuance was found during the content analysis done in some forums, and has an impact on the behavior of the learner. 
The study covered all structured forums. Learners work in the first two sequences, without any forum structure being provided to them. The relevance of their interactions in unstructured forums was also considered and their ability to build an organization that suited them was trusted. The learners' perceptions of the effectiveness of collaborative work, in SGOL sequence 3 , where the forum is well organized according to the learning scenario, was found. It is clear that the structuring facilitates the use of the forum and its effectiveness for distance learning.

\section{B. Tutorial intervention to help learners collaborate}

In the same way, the tutorial intervention has an important place in the good realization of an open and remote training. In tutorial resolution \# 8 of Jacques Rodet in April 2018, he spoke about collaboration, in other words helping learners to collaborate. "The remote tutor must intervene with groups of learners. It is not up to him to play the role of team leader but rather to help learners, both collectively and individually, so that learners can achieve their goals of activities and training as well as a real autonomy of operation. Its interventions are based on the collaboration of learners whose main phases are as follows: the learners' involvement to the team, the team production and the evaluation of their team's activities”.

In this case, learners must get involve in the team, produce as a team, and evaluate the activities of their team.

Productivity is related to accomplishing tasks and achieving goals. Tutorial interventions help learners to collaborate. They are thus very diverse and marked by the different phases of the collaboration. Actions' learners help learners to accomplish their tasks and achieve their goals by keeping their collaboration alive.

In problem-based and project-based learning, according to Caroline Verzat and her colleagues [13], effective learning is inseparable from true collaboration among students. The tutor's role is often to facilitate collaboration, to create a space for socio-cognitive conflict between students and to be able to facilitate learning as part of a dynamic group of students.

\section{CONCLUSION}

It can be concluded that the behavior of a learner in front of the discussion forum does not have a direct effect on his cognition; and then the domination of collaboration is highlighted on the acquisition of knowledge in open and distance learning. Motivation is also an important factor for perseverance in training, and in the end, communication is also necessary to have success. The dynamism in the collaboration implies a strong interaction within the group, thus resulting in the effective production for the achievement of the common objective, and obviously improves the educational results.

\section{REFERENCES}

[1] M. Rakotomalala, L. Zakariasy, L. A. Rafanomezantsoa, N. F. Leaby, « Organisation du tutorat, une stratégie pour l'efficacité du dispositif de formation à distance ", Colloque international sur les TIC. 27-29 juin 2012, Antananarivo Madagascar, 2012.

[2] M. Rakotomalala, T. B. Ravaliminoarimalalason, F. Randimbindrainibe, "Models for Measuring Latent Variables in Asynchronous Learning ", ESRSA, International Journal of Engineering Research \& Technology, Vol. 7 Issue 04, pp 146-150, April-2018.

[3] J.F. Hair, B. Black, Babin B., R.E. Anderson, R.L. Tatham, «Multivariate data analysis », Pearson Prentice-Hall, 7ème ed, 928 pages, 2009.

[4] B. Albero, " L'autoformation dans les dispositifs de FOAD : instrumenter le développement de l'autonomie dans les apprentissages ", in Saleh I., Lepage D. et Bouyahi S. (dir.), Les TIC au coeur de l'enseignement supérieur, Laboratoire Paragraphe, Université Paris 8, novembre 2002

[5] M. Linard, « Conception de dispositifs et changement de paradigme en formation », Education Permanente $n^{\circ}$ 152, 2002

[6] J. M. Dutrénit, « La compétence sociale, diagnostic et Développement », L'Harmattan, Paris, 1997

[7] A. Dix, D. Ramduny-Ellis, \& J. Wilkinson., « Trigger analysis understanding broken tasks ». In : D. Diaper \& N. Stanton (Eds.), « The Handbook of Task Analysis for Human-Computer Interaction ». Mahwah : Erlbaum 2004.

[8] P. Dillenbourg, "What do you mean by collaborative learning? " In : P. Dillenbourg (Ed). Collaborative -learning : Cognitive and Computational Approaches. pp. 1 - 19. Oxford, Elsevier, 1996.

[9] R. Nachmias, D. Mioduser, A. Oren, \& J. Ram, «Web-supported emergent-collaboration in higher education courses ». Educational Technology \& Society, 3(3), pp. 94 -104, 2000.

[10] M.J. Baker, « Forms of cooperation in dyadic problem-solving. Revue d'Intelligence Artificielle », 16, 4 - 5, pp. 587 - 620. 2002.

[11] B. De Lièvre, C. Depover, A. Strebelle, « Les avis individuels sont-ils pris en compte lors d'une activité collaborative à distance ? ", In : P. Tchounikine, M. Joab, L. Trouche (Eds). " Environnements informatiques pour l'apprentissage humain », 2005, pp. 93-104. Montpellier, France, 2005.

[12] B. De Lièvre, G. Temperman. « Trois modalités de structuration d'un forum collaboratif : comment les étudiants les jugent-il ? » Journées communication et apprentissage instrumentées en réseau 2008, 987-274622138-3. <halshs-01112579>, 2008.

[13] C. Verzat, N. O’Shea et B. Raucent, « Réguler le leadership dans les groupes d'étudiants en APP », Revue internationale de pédagogie de \begin{tabular}{lll|l} 
l'enseignement $\quad$ supérieur & pp. 31-1
\end{tabular} 